\title{
Komunikasi Ritual Obiyem pada Etnis Tamil Hindu di Kota Medan
}

\author{
Ratna Sari Puspa, Suzy S. Azeharie \\ ratna.915160130@stu.untar.ac.id,suzya@fikom.untar.ac.id
}

Fakultas Ilmu Komunikasi Universitas Tarumanagara

\begin{abstract}
The Tamil Hindu ethnic community is spread across Indonesia, the majority live in Medan North Sumatra. Obiyem ritual is a religious activity believed by the Tamil Hindu ethnic community. The ritual has existed since the time of Bharatayudha and it is believed to eliminate bad karma for anyone who participates and performs the ritual. This ritual also obliges the devotees to make offerings to the Gods and Goddesses as a form of gratitude for giving abundance, maintain and protecting the universe. With the existence of ritual communication, the Tamil Hindu ethnic community in Medan can communicate and relate to the creator through the Obiyem ritual. This tradition is still carried out by the Tamil Hindu ethnic community to this day. The purpose of this study is to find out how the ritual communication is at the ceremony to the Tamil Hindu ethnic in Medan and what preparations are needed when the ritual is performed. Theories used in this research are communication theory, ritual communication and transcendental communication. The research method used was a phenomenological method with a qualitative descriptive approach. The data were obtained from in-depth interviews with three sources who understood about the ritual of Obiyem. The conclusion of this study is the ritual of Obiyem is a media used to communicate between humans and the Creator so that all bad karma is eliminated. It is also strengthen the relationship of Tamil Hindu ethnic society.
\end{abstract}

Keywords: obiyem, ritual communication, transcendental communication, tamil, hindu.

\begin{abstract}
Abstrak
Masyarakat etnis Tamil Hindu di Indonesia mayoritas berada di kota Medan, Sumatera Utara. Ritual Obiyem merupakan kegiatan keagamaan bagi etnis Tamil Hindu. Ritual Obiyem sudah ada sejak zaman Bharatayudha. Ritual ini dipercaya bisa menghapuskan karma buruk bagi siapapun yang ikut serta dan melakukan ritual ini. Ritual ini juga mewajibkan para jemaah untuk memberikan persembahan kepada para dewa dan dewi sebagai bentuk terima kasih karena sudah memberi kelimpahan, memelihara dan menjaga alam semesta. Dengan adanya komunikasi ritual masyarakat etnis Tamil Hindu di Medan dapat berkomunikasi dan berhubungan dengan sang pencipta melalui ritual Obiyem. Ritual ini masih dilaksanakan oleh masyarakat etnis Tamil Hindu sampai saat ini. Penelitian ini ingin mengetahui bagaimana komunikasi ritual Obiyem pada etnis Tamil Hindu di kota Medan dan apa saja persiapan yang dibutuhkan pada saat ritual Obiyem dilakukan. Teori yang digunakan dalam penelitian ini adalah teori komunikasi, komunikasi ritual dan komunikasi transendental. Penelitian ini menggunakan metode fenomenologi dengan pendekatan deskriptif kualitatif. Data diperoleh dari hasil wawancara mendalam dengan narasumber yang mengetahui ritual Obiyem. Kesimpulan dari penelitian ini adalah ritual Obiyem merupakan media yang digunakan untuk berkomunikasi antara manusia dan sang pencipta untuk menghapuskan karma buruk. Komunikasi ritual ini juga dilakukan untuk mempererat hubungan masyarakat etnis Tamil Hindu.
\end{abstract}

Kata Kunci: obiyem, komunikasi ritual, komunikasi transendental, tamil, hindu. 


\section{Pendahuluan}

Etnis Tamil merupakan salah satu etnis di kota Medan. Etnis Tamil ini merupakan cikal bakal keberagaman budaya India yang ada di kota Medan. Persebaran etnis Tamil meninggalkan jejak kebudayaan di kota Medan (Riyaf, 2015). Pada abad 19 etnis Tamil menjelajahi laut menggunakan perahu layar dari India dan mendarat di pantai pulau Sumatera untuk berjualan, menyebarkan kebudayaan dan kepercayaan mereka dari Tamilnadu (Kobalen, 2020). Di dalam etnis Tamil, terdapat etnis Tamil Hindu yang masih sangat lekat dengan adanya ritual pemujaan. Terdapat beberapa kuil pelaksanaan ritual pemujaan dan upacara keagamaan di Medan. Kuil ini merupakan rumah ibadah atau tempat sembahyang bagi etnis Tamil Hindu (Kobalen, 2020).

Salah satu ritual yang masih dilaksanakan oleh etnis Tamil Hindu adalah ritual Obiyem. Obiyem merupakan sebuah ritual keagamaan Hindu yang dilakukan oleh seseorang, keluarga, ataupun organisasi yang memiliki niat atau hajatan tertentu. Ritual ini hanya boleh dipimpin oleh seorang Pandita karena kedudukan Pandita di kepercayaan Hindu adalah seorang cendekiawan atau seorang guru yang bertugas untuk membimbing Bhakta atau jemaah ke jalan yang benar yaitu melayani Tuhan.

Ritual Obiyem ditujukan untuk menghapus karma buruk dengan cara melakukan pemujaan kepada dewa dewi seraya menyertakan persembahan, beramal dan memberi hidangan untuk para Bhakta yang ikut serta pada ritual ini. Karma merupakan hal yang sangat dipercayai oleh umat Hindu. Oleh karena itu, ritual Obiyem dilaksanakan secara turun-menurun dan wajib dilestarikan.

Menurut Rahmansyah, keberagaman budaya bisa dilihat dalam beberapa bentuk, salah satunya adalah ritual, yang menjadikan tanah air kita memiliki potret mengenai keberagaman budaya (Azeharie, 2019). Sebagaimana definisi komunikasi yang dikemukakan oleh West dan Turner (2007), merupakan proses sosial antar seseorang atau individu dengan menggunakan simbol-simbol untuk menciptakan dan menafsirkan makna dalam lingkungan mereka. Pola komunikasi yang terbentuk dalam pandangan ritual adalah berupa upacara sakral atau suci yang dilakukan setiap manusia secara beramai-ramai dan berkumpul (Couldry, 2005). Komunikasi transendental adalah komunikasi yang menghubungkan manusia dengan Tuhan (Mulyana, 1999).

Dari sejumlah konsep tersebut dapat dirangkum bahwa ritual Obiyem merupakan budaya etnis Tamil Hindu yang menjadi salah satu kekayaan budaya di Indonesia. Ritual Obiyem dilakukan dengan memberikan persembahan kepada dewa dan dewi sebagai simbol yang menjadi mediasi agar terjalin komunikasi antara Bhakta dengan Tuhan. Hal ini karena ritual adalah media komunikasi antara manusia dengan Tuhan yang biasanya dilakukan secara bersama-sama. Ritual Obiyem bisa terlaksana dengan baik jika keadaan seseorang atau suatu kelompok berada dalam keadaan transendental atau keadaan dengan pikiran yang halus agar proses komunikasi yang terjalin antara manusia dengan Tuhan terjalin seperti yang diinginkan.

Peneliti ingin mengetahui bagaimana komunikasi ritual Obiyem pada etnis Tamil Hindu di kota Medan, dan apa saja perlengkapan dan persiapan pada saat ritual Obiyem dilakukan. Alasan lainnya adalah karena penelitian mengenai ritual Obiyem pada etnis Tamil Hindu belum ada yang meneliti sebelumnya.

\section{Metode Penelitian}

Penulis menggunakan pendekatan kualitatif deskriptif dengan metode fenomenologi. Penelitian yang sifatnya deskriptif bertujuan memberikan suatu 
gambaran terhadap suatu masalah, gejala, fakta, peristiwa, dan realita secara luas dan mendalam sehingga tercipta suatu pengertian baru (Semiawan, 2010). Pendekatan kualitatif paling tepat untuk menjelaskan tujuan dari penelitian ini yaitu untuk mengetahui bagaimanakah komunikasi ritual Obiyem pada etnis Tamil Hindu di kota Medan.

Sementara, fenomenologi adalah suatu gerakan yang bertolak belakang dengan filsafat yang tetap, dengan momentum yang dinamis, yang perkembangannya ditentukan oleh prinsip yang terkandung di dalamnya, dan juga oleh hal-hal struktur wilayah yang dihadapinya (Spiegelberg, 2006). Fenomenologi merupakan ilmu yang mempelajari fenomena yang nyata dari suatu lingkungan kehidupan dan orang-orang yang berinteraksi di lingkungan tersebut dari segi sudut pandang hingga kebiasaan. Salah satu tahapan pengumpulan data dalam penelitian fenomenologi yaitu dengan cara wawancara (Creswell, 2010). Dalam penelitian ini penulis mewawancarai tiga narasumber yang mengetahui ritual Obiyem serta etnis Tamil Hindu.

\section{Hasil Temuan dan Diskusi}

\section{a. Ritual Obiyem}

Ritual Obiyem sudah ada sejak zaman Bharatayuda. Obiyem merupakan sebuah ritual keagamaan Hindu yang dilakukan oleh seseorang, suatu keluarga ataupun suatu organisasi yang memiliki niat atau hajatan tertentu. Ritual ini hanya boleh dipimpin oleh seorang Pandita karena kedudukan Pandita di kepercayaan Hindu adalah seorang cendikiawan atau seorang guru yang bertugas untuk membimbing Bhakta atau jemaah ke jalan yang benar yaitu melayani Tuhan. Ketika memimpin upacara Obiyem, seorang Pandita harus paham mantra dan doa suci berdasarkan kitab Veda dan kisah Ramayana. Ritual ini ditujukan untuk menghapus karma buruk dengan cara melakukan pemujaan kepada dewa dewi sambil menyertakan persembahan, beramal dan memberi hidangan untuk para Bhakta yang ikut serta pada ritual ini (wawancara dengan Punis Pri pada 10 Mei 2020).

Obiyem dipercaya sebagai media untuk menyampaikan segala permohonan yang dipanjatkan kepada para dewa dewi. Setiap prosesinya dipercaya bertujuan untuk mensejahterakan seluruh anggota keluarga serta agar Bhakta yang mengikuti dijauhkan dari hal negatif atau pembawa sial. Karma merupakan hal yang sangat di percaya oleh umat Hindu. Oleh karena itu, ritual Obiyem ini dilaksanakan secara turunmenurun dan wajib dilestarikan (hasil wawancara terhadap Pandita Jaysangker yang di lakukan pada tanggal 27 Februari 2020 pukul 20:00 WIB).

\section{b. Komponen Komunikasi Ritual}

Menurut Koentjaraningrat ada komponen pokok yang terdapat dalam pelaksanaan ritual yaitu:

1) Tempat berlangsungnya ritual

Tempat yang difungsikan untuk pelaksanaan suatu ritual adalah tempat yang khusus dan bersifat keramat, hanya orang berkepentingan saja yang boleh mengakses tempat tersebut (Koentjaraningrat, 1967).

Berdasarkan hasil wawancara dengan Punis Pri tempat berlangsungnya ritual Obiyem hanya boleh dilaksanakan di kuil yang merupakan tempat berkumpul dan berdoa masyarakat umat Hindu dan tempat diletakannya arca para dewa dan 
dewi (wawancara dengan Punis Pri melalui pesan WhatsApp pada 10 Mei 2020 pukul 19:25 WIB).

Gambar 1. Kuil tempat pelaksanaan ritual Obiyem

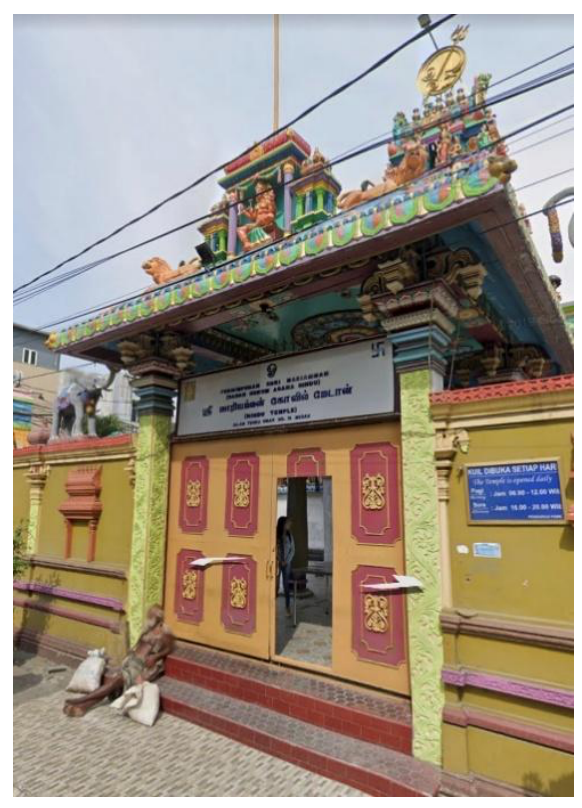

Sumber: dokumentasi narasumber

2) Waktu pelaksanaan ritual

Waktu pelaksanaan ritual adalah saat-saat khusus yang dirasakan tepat dan baik untuk melaksanakan suatu ritual (Koentjaraningrat, 1967). Narasumber, Punis Pri mengatakan bahwa ritual Obiyem boleh dilakukan kapan saja tergantung dewa apa yang dipercaya pihak keluarga, seseorang atau suatu organisasi. Setiap dewa dan dewi memiliki hari besar masing-masing. Pada zaman sekarang, ritual Obiyem biasa dilaksanakan pada malam hari setelah seluruh umat selesai beraktifitas (wawancara dengan Punis Pri tanggal 10 Mei 2020).

3) Benda-benda ritual

Benda-benda ritual merupakan alat-alat dan ornamen yang difungsikan untuk menjalankan suatu ritual seperti wadah untuk tempat sajen, alat kecil seperti sendok, pisau dan lain-lain (Koentjaraningrat, 1967).

Pandita Jaysangker menjelaskan bahwa benda-benda ritual adalah barangbarang yang digunakan pada saat ritual Obiyem seperti nampan yang digunakan untuk meletakkan persembahan atau Arcenei, lampu suci, lonceng dan wadah air yang semuanya terbuat dari kuningan dan digunakan sebagai sarana untuk melaksanakan ritual Obiyem (wawancara dengan Pandita Jaysangker pada 8 Mei 2020).

4) Orang-orang yang terlibat

Orang-orang yang terlibat dalam ritual adalah pemimpin jalannya ritual dan orang yang paham tentang suatu ritual (Koentjaraningrat, 1967).

Berdasarkan hasil wawancara penulis dengan Punis Pri, orang-orang yang terlibat dalam ritual Obiyem adalah Pandita sebagai pemimpin pelaksanaan ritual, 
lalu pihak yang ingin membuat ritual yaitu seseorang, sebuah keluarga atau sebuah organisasi dan pihak terakhir adalah para Bhakta yaitu jemaah etnis Tamil Hindu (wawancara dengan Punis Pri pada 10 Mei 2020 WIB).

Koentjaraningrat menjelaskan terdapat dua kegiatan yang terkait dalam pelaksanaan suatu ritual yaitu:

1) Berdoa

Berdoa adalah unsur yang terdapat dalam semua jenis ritual. Doa adalah ucapan dan keinginan manusia kepada Tuhan dan leluhur dan juga doa merupakan penghormatan dan pujian kepada Tuhan dan leluhur. Biasanya doa diiringi dengan gerak dan sikap menghormat serta merendahkan diri terhadap para leluhur (Koentjaraningrat, 1967).

Hal ini sesuai dengan yang dijelaskan oleh Pandita Jaysangker bahwa persembahan yang akan disajikan didoakan terlebih dahulu oleh Pandita dan pihak yang melakukan ritual Obiyem. Doa yang dipanjatkan berisi harapan dan permohonan agar terhapus dari segala karma buruk (wawancara dengan Pandita Jaysangker via WhatsApp pada 8 Mei 2020 pukul 17:16 WIB).

2) Bersaji

Bersaji adalah perbuatan-perbuatan untuk menyajikan makanan, benda-benda atau yang lainnya kepada dewa dewi dan roh-roh nenek moyang. Bersaji menjadi suatu kebiasaan dan dianggap sebagai suatu aktivitas yang secara otomatis akan menghasilkan apa yang dimaksud (Koentjaraningrat, 1967).

Pandita Jaysangker menjelaskan bahwa setelah persembahan didoakan, persembahan akan dibagikan kepada seluruh Bhakta yang hadir dalam ritual Obiyem agar semua yang terlibat dalam ritual ini bisa mendapatkan berkah (wawancara dengan Pandita Jaysangker pada 8 Mei 2020).

Gambar 2. Persembahan atau Sesaji ritual Obiyem

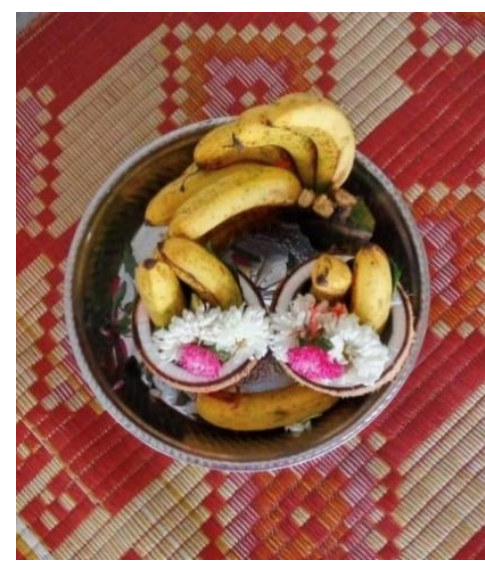

Sumber: Dokumentasi Narasumber 
Gambar 3. Sesaji di atas altar sembahyang

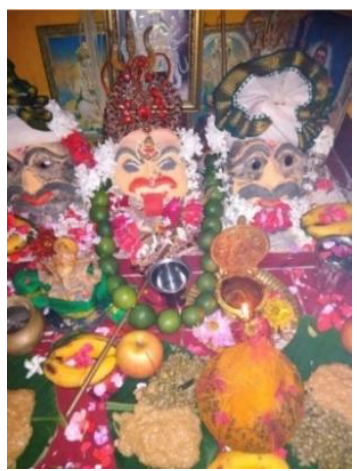

Sumber: Dokumentasi Narasumber

\section{Simpulan}

Komunikasi ritual merupakan komponen penting dalam pelaksanaan ritual Obiyem. Dengan adanya komunikasi ritual masyarakat etnis Tamil Hindu di Medan dapat berkomunikasi dan berhubungan dengan sang pencipta melalui ritual Obiyem.

Ritual Obiyem merupakan sebuah ritual yang mempersembahkan berbagai macam persembahan dan sepuluh persen penghasilan para Bhakta kepada dewa dan dewi atau sang pencipta, yang dipercaya untuk menghapus segala karma buruk. Selain itu ritual ini ditujukan sebagai penghargaan dan ucapan terima kasih kepada sang pencipta karena sudah menjaga dan memelihara alam semesta.

Ritual Obiyem merupakan media yang menggambarkan hubungan antara manusia dan Sang Pencipta dan mempererat hubungan masyarakat etnis Tamil Hindu.

\section{Ucapan Terima Kasih}

Terima kasih kepada semua pihak yang telah mendukung, dan membantu penulis dalam menyelesaikan penelitian ini sampai selesai.

\section{Daftar Pustaka}

Azeharie, Suzy, Sinta Paramita dan Wulan Purnama Sari. (2019). Studi Budaya Nonmaterial Warga Jaton. Jurnal. ASPIKOM. 3(6). 1153-1162.

Couldry, Nick. (2005). Media Rituals Beyond Functionalism. Thousand Oaks: SAGE Publications.

Cresswell, John.W. (2010). Research Design. Thousand Oaks: SAGE Publications. Koentjaraningrat. (1967). Beberapa Pokok Antropologi Sosial. Jakarta. Dian Rakyat. Mulyana, Deddy. (1999). Nuansa-Nuansa Komunikasi. Bandung: PT.RemajaRosdakarya.

Riyaf, A. (2015). Perubahan Rangkaian Ritual Thaipusam Di Kuil Sree Soepramaniem Nagarattar Pada Etnik Tamil Di Kota Medan.

Semiawan, Conny.R. (2010). Metode Penelitian Kualitatif. Jakarta: Grasindo.

Spiegelberg, Herbert. (2006). Principles and Practice of Research in Midwifery London: Churchill Livingstone.

West, Richard L. and Turner, Lynn H. (2007). Introducing Communication Theory Analysis and Application. New York: McGraw Hill Education 